\title{
Painting the history of cardiology
}

David Lomas

The panels that the Mexican muralist Diego Rivera created for the Mexican National Institute of Cardiology in the 1940s evince a populist concern and celebrate medical technology

The murals Diego Rivera executed for the National Institute of Cardiology in Mexico City (figures 1 and 2) are a testament to his talents as a painter as well as to his prodigious energy. The History of Cardiology consists of two panels of $6 \mathrm{~m}$ by $4 \mathrm{~m}$ and were completed in time for the inauguration of the new institute building on 18 April 1944.

Rivera is the 20th century's greatest exponent of fresco painting. A bravura example of his virtuosity can be found at the bottom right of the first panel, near where he signed the work. The 16 th century anatomist Andreas Vesalius holds in his bloodied hand a human heart, its surface mottled and glistening, having been dissected from the pallid cadaver whose head appears to jut into our space. Confronting the viewer almost at eye level with this gory trompe l'oeil spectacle, Rivera has pulled off a real heart stopper.

Ignacio Chávez, who commissioned the murals from Rivera, was a mover and shaker in the cardiology profession. Returning to Mexico in 1927 after two years of specialist training in Paris, Chávez set about reforming and promoting Mexican cardiology. He was the founding editor of the Latin American Archives of Cardiology and Haematology and director of the National Institute of Cardiology until 1960. Both Chávez and Rivera were founding members of an elite

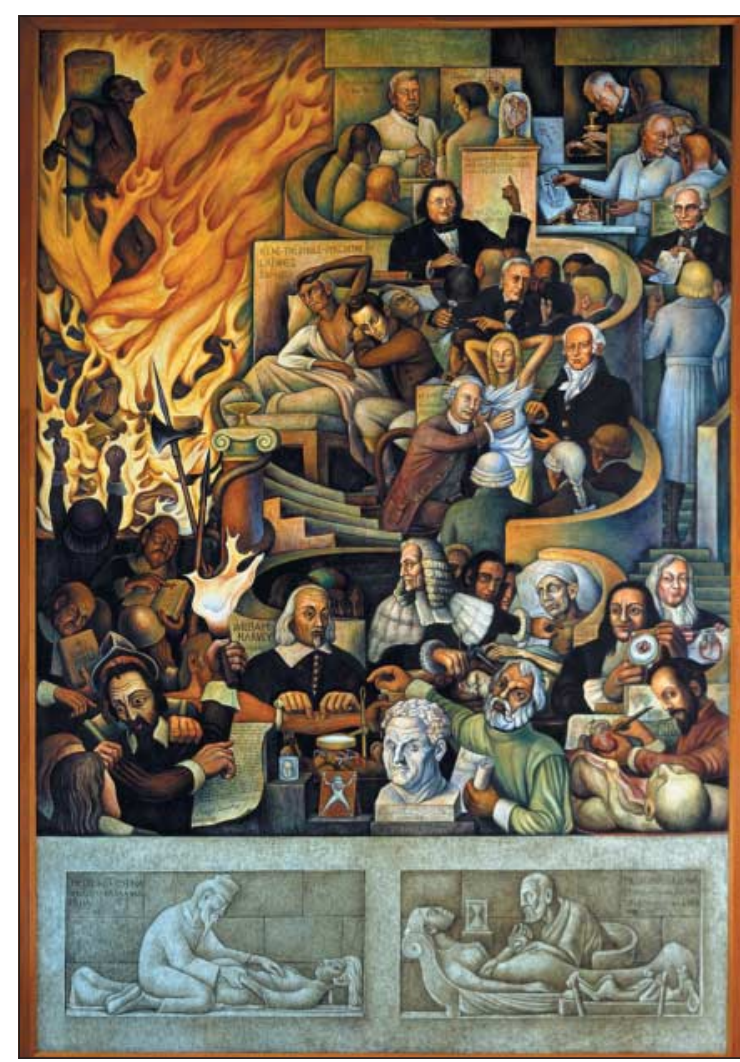

Fig 1 History of Cardiology (first panel) academy, the Colegio Nacional, formed in May 1943 and made up of the country's most prominent writers, artists, philosophers, and scientists. One can imagine the idea for the murals being dreamt up by Chávez in this setting, with construction of the new institute building already under way. Coinciding with the second Inter-American Congress of Cardiology in 1946, which was hosted by the institute, Chávez produced a lavishly illustrated booklet about the History of Cardiology in a small edition of 130 copies. ${ }^{1}$ It is clear from Chávez's account that Rivera was working to a strictly defined brief. He was offered guidance in the form of copious notes by Chávez, who also supplied the artist with the sources from which the pantheon of characters was assembled.

\section{Onwards and upwards}

One possible influence may have been a set of frescoes depicting the history of medicine painted by a follower of Rivera a few years earlier at the University of California Medical School in San Francisco. Bernard Zakheim, a Jewish émigré from Poland, travelled to Mexico to work alongside Rivera in the 1930s, and after his return to the San Francisco Bay area undertook a number of mural commissions. Rivera

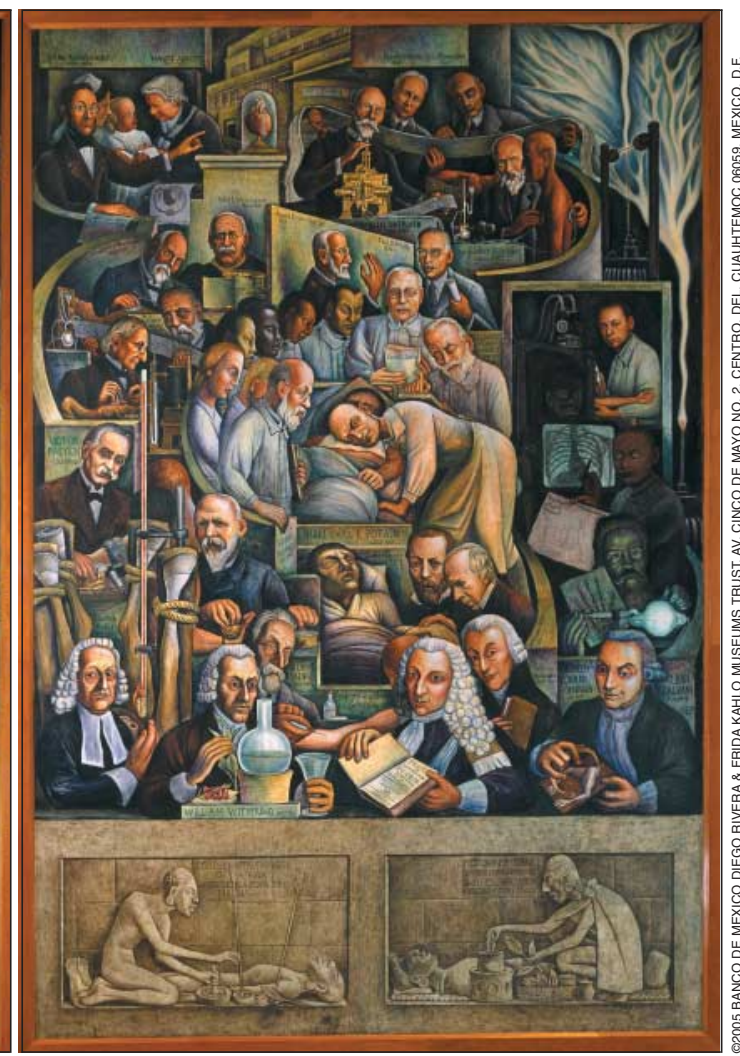

Fig 2 History of Cardiology (second panel)
School of Arts, Histories, Cultures, University of Manchester, Manchester M13 9PL

David Lomas reader in art history david.c.lomas@ manchester.ac.uk

BMJ 2005;331:1533-5 
very likely saw the murals, which pitched modern medicine against religious and superstitious practices, during a stay in San Francisco in 1940-1. Chávez may also have known about the murals from a book published in Mexico in 1942 by the physiologist J J Izquierdo. ${ }^{2}$ Chávez's notes for Rivera show that the clash and eventual triumph of science over superstition were present from the outset in his conception of the cardiology murals.

Chávez wanted Rivera to paint a tribute to the great founders of modern cardiology. In his notes for Rivera, Chávez emphasised the theme of struggle between adversaries and an arduous ascent. The picture "should indicate the ascending trend of knowledge and if possible should express how slow and difficult has been the advance, how each of those men had to fight routine, prejudice, ignorance and fanaticism [...] If you could find the way, it would be beautiful to paint this group of men moving, striving in an upward march." Rivera responded by incorporating flights of steps and scalloped niches in the composition that lead the eye ever upwards to the doorstep of the National Institute of Cardiology, glimpsed at the top of the second panel.

The struggle of medicine against religious prejudice is a salient theme of the murals that engenders its own saints and martyrs. Michael Servetus (Miguel Serveto), the Spanish physician and theologian who described the pulmonary circulation, was burnt at the stake as a heretic on Calvin's orders. At lower left in the first panel, Servetus is tormented by priestly accusers brandishing wooden crosses and bibles and

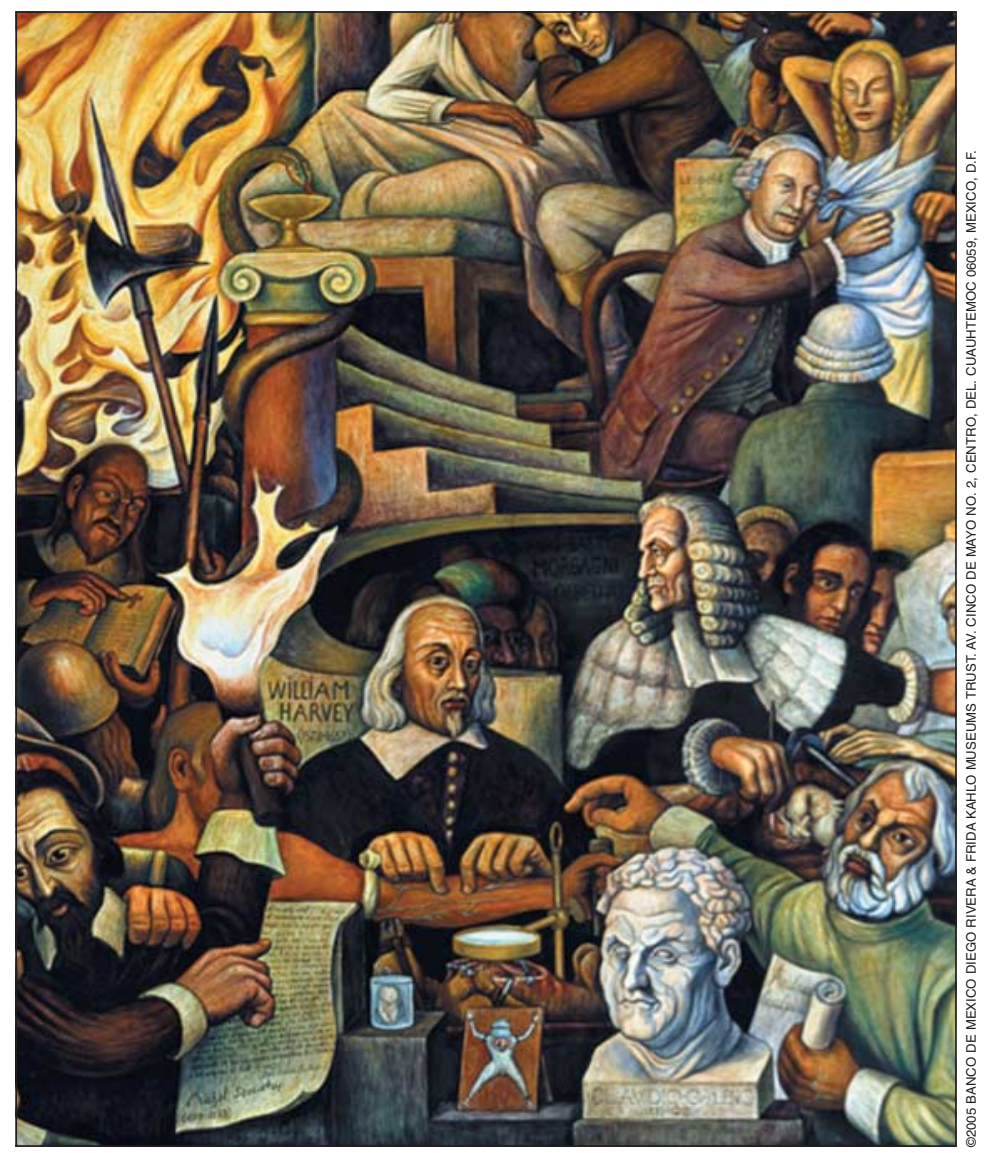

Fig 3 Detail of first panel: William Harvey and, to his lower right, Servetus manhandled by an arresting militiaman. This scene allows Rivera to take a swipe at one of his bugbears, the collusion of church and army.

\section{Laboratory meets bedside}

The decision to arrange the murals in the form of two upright panels facing each other enabled the historical development of cardiology to be presented as the outcome of a more complex interplay of factors than would have been possible with a single vertical timeline. It is probable that Rivera followed Chávez's suggestion in grouping, on the one side, those who contributed to knowledge about the heart and circulation (anatomists and physiologists) and, on the other, the clinical doctors responsible for diagnostic or therapeutic advances.

This reflects a view of modern cardiology as the product of a symbiosis between laboratory and bedside that was also embodied in the design of the new institute building. As a Trotskyite Marxist, Rivera was disposed to see technology as an independent motor of historical progress. The motif of a lightning conductor, which harnesses natural energy and channels it to the investigative apparatus arrayed in the contiguous section of the second panel, is recycled from his destroyed Rockefeller Center mural, where the overall theme is humanity's control of its destiny through the mastery of science and technology.

Colour plays a decisive role in differentiating but also linking the two panels. The flames licking at Servetus cast a reddish glow across the whole of the first panel, while the lightning flash at the upper right of the second panel suffuses it with a bluish hue. Chávez notes the resulting red and blue coloration but surprisingly fails to grasp its significance. It is probable, in fact, that Rivera was directly inspired by William Harvey's discovery that arterial and venous sides of the circulation comprise a single circuit joined by the heart, overturning longstanding Galenic views. Harvey's famous essay, De motu cordis (1628), had become available in a 1936 Spanish translation by J J Izquierdo. $^{3}$

My conjecture is that this volume was among the source material that Chávez supplied Rivera with. Harvey, who occupies pride of place in the first of the first panel (figure 3), is a composite of two images reproduced by Izquierdo, one a portrait engraving and the other a diagram taken from his original essay demonstrating the flow of blood in the veins. In keeping with Izquierdo's view of Harvey as a pioneer of the experimental method, Rivera shows him surrounded by vivisection specimens and also what appears to be a human fetus.

The four smaller panels at the bottom of the murals take the form of a fictive sculptural relief in which Rivera represents medicine of the "pre-Christian" era (the era before the European invasion of Mexico). They would seem to play no part in Chávez's vision of the unfolding history of cardiology, as he makes no mention of them in his account of the murals.

A clue to their possible significance can be found in a highly influential theory espoused by José Vasconcelos, a former minister for education with close ties to the Mexican muralist movement, in a book entitled The Cosmic Race (first published in 1925). ${ }^{4}$ Reflecting a 
mood of euphoria after the Mexican revolution, Vasconcelos claimed that a new universal era of humanity was about to be born and that its birthplace would be in Latin America. The fifth race-the cosmic race of the future-would come about as a result of the miscegenation of the four races that had been responsible for the major civilisations up until the present. What he saw as especially favourable about Latin America was the mixture of ethnic stocks in the population.

Following this argument, the lower register of the History of Cardiology murals may be seen as bringing together the past civilisations whose fusion and synthesis would engender the universal scientific culture of the future. Vasconcelos was a founding member of the Colegio Nacional, and hence Rivera would have been in contact with him around this time. Also supporting this reading is Rivera's portrayal of a diverse array of ethnic types in the guise of medical students, embodying the future of medicine (figure 4). Conspicuous is his inclusion of a woman in the group, insisting that although women may have been excluded from the past of cardiology they must be part of its future.

\section{Giving indigenous medicine its due}

In Mexico today folk medicine is widely used among the indigenous population, where it competes on an everyday basis with Western medicine. By introducing references to indigenous medical practices, albeit couched in the form of a distant archaeological past, Rivera forces the modern and the indigenous into a proximity that begins to undercut the progressivist assumptions that informed Chávez's brief. Take, for instance, the vertical alignment in the first panel of a sacrificial animal in a scene of early Greek medicine with the vivisection specimens immediately above it (one of which, a dog, closely echoes the animal in the scene below but with its orientation reversed). The Greek physician who examines an animal's entrails to prognosticate about his patient is likened to Harvey dissecting an animal to learn about human physiology; the process of observation and inference is equivalent in each case.

In the second panel, Rivera intimates a rapport between indigenous and modern uses of therapeutic drugs. This is most obvious at the lower right, where an Aztec healer or curandero administers a herbal infusion extracted from the leaves and flowers of yolloxochitl or "heart flower," used by the Aztecs for the treatment of heart ailments. This figure is deliberately echoed in the panel above by a portrait of William Withering, the English physician who extracted the active principle from the foxglove plant and determined a therapeutic dose that avoided the toxic effects that had restricted its use before then. Chávez describes Withering as having "wrested digitalis from the empiricism of herbalists," whereas it seems that Rivera has placed the accent instead upon the similarity of the traditional herbalist to the modern physician.

Also in this panel Rivera has shown in the bottom register African natives using strophanthin as an arrow tip poison and, above them, standing near Withering's left shoulder, the German physician

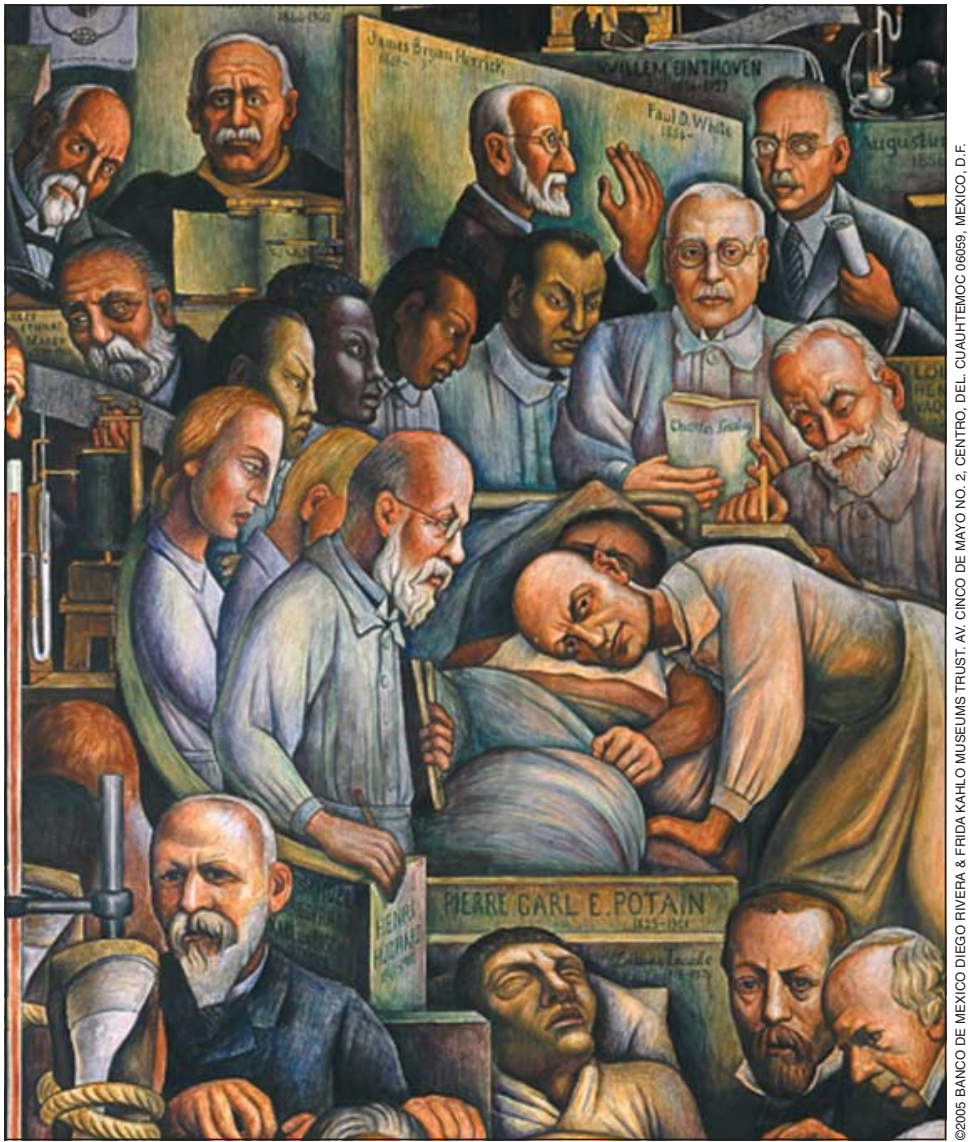

Fig 4 Detail of second panel: The French cardiologist Charles Laubry (1872-1960) with medical students. One of these, to his immediate right, is a portrait of Chávez

Albert Fraenkel, who is credited with the discovery that the same drug injected into the bloodstream has a therapeutic value.

In recent decades the pendulum swing of popular opinion has tended to favour the more ambivalent and edgy, private work of Rivera's wife, the painter Frida Kahlo. The public rhetoric of mural painting has become unfashionable and is liable to be dismissed as one dimensional propaganda. This view is belied by Rivera's complex negotiation with the issues of indigenism and technological modernity. Certainly his populism was genuine, and he understood better than some of his latter day critics that an issue for all people regardless of ethnicity was (and remains) one of equality of access to the fruits of technology. Though I am no cardiologist, to my mind his heart was in the right place.

I thank Irene Barajas and Emiliano García, who found and photographed the murals. I am grateful also to Maria del Carmen Lacy Niebla of the Instituto Nacional de Cardiología and Valerie Wheat of the Library archive at the University of California at San Francisco.

1 Chávez I. Diego Rivera, sus frescos en el instituto nacional de cardiologia. Mexico City, 1946.

2 Izquierdo JJ. Los cuandros murales de la Facultad de Medicina de San Francisco, California. Mexico City: Imprente Universitaria de México, 1942.

Izquierdo JJ. Harvey, iniciador del methodo experimental. Mexico City: Ediciones Ciencia, 1936.

4 Vasconcelos J. The cosmic race; la raza cósmica (bilingual edition). Baltimore and London: Johns Hopkins University Press, 1997. 